\title{
Produção e nutrientes minerais de milheto forrageiro e sorgo sudão adubado com soro de leite
}

\author{
Waldirene B. B. Morrill ${ }^{1}$, Mario M. Rolim², Egídio Bezerra Neto ${ }^{3}$, \\ Elvira M. R. Pedrosa ${ }^{2}$, Veronildo S. Oliveira ${ }^{2} \&$ Gledson L. P. de Almeida ${ }^{2}$
}

RESU MO

Este estudo objetivou avaliar o desenvolvimento e teores de macronutrientes presentes no milheto e no sorgo Sudão, em resposta à aplicação de doses de soro de leite ao solo. 0 experimento foi conduzido com solo em vasos com capacidade de $8 \mathrm{dm}^{3}$ em ambiente protegido utilizando-se delineamento inteiramente casualizado em arranjo fatorial 2 (aplicação única e parcelada) × 5 (doses de soro) com quatro repetições. As doses foram equivalentes a: 0, 167, 333, 667 e $1000 \mathrm{~m}^{3}$ ha-1 de soro de leite, determinadas com base no teor de K. $O$ soro foi aplicado em dose única, 10 dias antes da semeadura e em dose parcelada (50\% 10 dias antes da semeadura e 50\% 20 dias após a emergência das plantas). Após 42 dias realizou-se a colheita e se determinaram altura e massa seca da parte aérea. A trituração da massa seca foi realizada para o preparo de extratos, com vista às determinações analíticas dos nutrientes, $\mathrm{P}, \mathrm{Na}, \mathrm{K}, \mathrm{Ca}$ e M g. O s resultados mostraram que para produção de massa seca no manejo de aplicação dose única ocorreu, a partir da dose equivalente a $667 \mathrm{~m}^{3}$ ha-1 de soro de leite, diminuição na produção, em ambas as culturas, enquanto para a aplicação parcelada a redução se deu a partir da dose $167 \mathrm{~m}^{3} \mathrm{ha}^{-1}$.

Palavras chave: água residuária, forragem, Pennisetum glaucum, Sorghum bicolor

\section{Productivity and mineral nutrients in millet and Sudan grass fertilized with whey}

\begin{abstract}
A B ST RAC T
The objective of this study was to evaluate the development and levels of macronutrients present in millet and sudan grass in response to fertilization of the soil with whey. The experiment was carried out under greenhouse using $8 \mathrm{dm}^{3}$ pots, in a completely randomized design with a 2 (partitioned and total application) $\times 5$ (doses of whey) factorial arrangement with four replications. The doses were equivalent to 0,167 , 333, 667 and $1000 \mathrm{~m}^{3} \mathrm{ha}^{-1}$ of whey and were determined based on the amount of $\mathrm{K}^{+}$in the whey. The whey was applied in total 10 days before sowing and in split doses $(50 \% 10$ days before sowing and $50 \% 20$ days after emergence of the seedlings). Plants were harvested after 42 days and the dry weight and shoot height were determined. Plant dry mass was ground to prepare extracts for determination of the nutrients: P, N a, K, Ca and M g. Production of dry matter in both species started to decrease from 667 $\mathrm{m}^{3} \mathrm{ha}^{-1}$ of whey in total application, whereas in partitioned application the reduction in dry matter yield began from $167 \mathrm{~m}^{3} \mathrm{ha}^{-1}$ in both crops.
\end{abstract}

Key words: wastewater, forage, Pennisetum glaucum, Sorghum bicolor

\footnotetext{
${ }^{1}$ D outoranda do Programa de Pós-graduação em Engenharia Agricola/U FRPE, Av. Dom Manuel de Medeiros, s/n, Dois Irmãos, CEP 52171-900, Recife, PE. Fone: (81) 3320-6276. E-mail: wbbm.2006@hotmail.com

2 DTR - UFRPE. E-mail: rolim@dtr.ufrpe.br; elvira.pedrosa@dtr.ufrpe.br; gledson81@hotmail

3 DQ -U FRPE. E-mail: egidio@dq.ufrpe.br
} 


\section{INTRODUÇÃO}

O soro de leite é um subproduto resultante da fabricação de queijos, cuja composição química apresenta quantidades consideráveis de lactose, proteínas solúveis e sais minerais. Durante muito tempo o soro foi considerado um resíduo de baixo ou nenhum valor comercial usado na alimentação de animais ou descartado em efluentes sem qualquer tratamento (Almeida et al., 2001; Barbosa et al., 2010).

No Brasil, a produção de bebidas lácteas é uma das principais opções de aproveitamento do soro do leite (Capitani et al., 2005). Apesar de nos últimos anos a legislação que trata da qualidade do efluente da indústria de laticínios se ter tornado mais rigorosa com relação ao destino do soro de queijo, na tentativa de preservar o meio ambiente, $50 \%$ do soro de queijo produzido no Brasil ainda são descartados na natureza, como resíduo (Silveira, 2004).

O estudo da utilização de resíduos agroindustriais no solo visando à produção de forragens tem indicado bons resultados quanto à produtividade. Gheri et al. (2003) detectaram, analisando os teores nutricionais do soro de leite ácido utilizado em sua pesquisa, os níveis de alguns nutrientes essenciais contidos no soro ácido (N, 700; Ca, 900; Mg, 100; K, 1520; P, 500; C, 28000; S, 50, todos em $\mathrm{mg} \mathrm{L}^{-1}$ ).

Por sua vez, as pastagens representam a fonte de alimento muito importante na criação de ruminantes. Na região Nordeste do Brasil cerca de 70\% de sua área estão incluídos no semiárido, caracterizado por condições climáticas que causam variação sazonal na produção de forragem (Silva et al., 2011). Desta forma, a suplementação volumosa tem-se baseado na utilização de recursos forrageiros adaptados à seca. Neste contexto, o milheto forrageiro (Pennisetum glaucum L.) e o sorgo sudão (Sorghum bicolor var. sudanense L.) se vêm destacando por apresentarem maior flexibilidade de épocas de plantio e alto potencial produtivo, podendo constituir alternativas de forragem para intensificar a produção animal, principalmente em épocas de escassez de alimento (Simili et al., 2008).

Segundo Guimarães et al. (2005), o milheto apresenta grande potencial forrageiro devido ao alto valor nutritivo e à sua grande versatilidade de utilização, de vez que se trata de uma cultura de fácil instalação e que requer poucos insumos, pois a planta tem um sistema radicular profundo e vigoroso, o que a torna eficiente no uso de água e nutrientes (Payne, 2000) sendo, ainda, um cereal de grande importância mundial, considerado excelente alternativa para a produção de grãos e forragem (Café et al., 2002).

$\mathrm{O}$ milheto forrageiro apresenta acentuada produção de forragem, que pode chegar a $20 \mathrm{tha}^{-1}$ de massa seca ao longo do seu ciclo de crescimento. É uma planta que se adapta a solos de baixa fertilidade, resistente à seca e calor excessivo, possuindo crescimento rápido e sistema radicular profundo apresentando, também, bom desenvolvimento em solos ácidos e com baixo teor de matéria orgânica, além de promissor para muitos solos brasileiros (Castro, 2002; Ingrid \& Moojen, 2002).

Por outro lado, o sorgo é uma gramínea rústica de rápido crescimento e bastante utilizada sob diversas formas, em todo o mundo. De acordo com Reis (1999) o sorgo apresenta grande potencial de produção de forragem na região Nordeste, por sua capacidade de adaptação, tolerância a temperaturas elevadas e por possuir características de xerofilia. Para Oliveira et al. (2002), este diferencial é significativo em sistemas de produção em regiões sujeitas a secas e que não disponham de irrigação. A produtividade média de sorgo no Brasil ainda é considerada baixa, girando em torno de $2.276 \mathrm{~kg} \mathrm{ha}^{-1}$ de grãos, em que suas precipitações irregulares, a fertilidade do solo e as baixas aplicações de fertilizantes, constituem os principais fatores responsáveis pela baixa produtividade nas áreas destinadas à produção dessas plantas (Aguiar et al., 2007).

Ante o exposto, o objetivo deste trabalho foi avaliar o desenvolvimento, produtividade e teores de macronutrientes presentes no milheto forrageiro e sorgo Sudão, em resposta à aplicação de doses de soro de leite no solo.

\section{Material e MÉTODOS}

O experimento foi conduzido em ambiente protegido, durante 42 dias, no Departamento de Tecnologia Rural da Universidade Federal Rural de Pernambuco (UFRPE), no período de outubro a novembro de 2009.

O soro de leite utilizado foi do tipo doce, resultante da fabricação de queijo de coalho, fornecido pela Fazenda Roçadinho localizada no município de Capoeiras, PE. A determinação química do soro (Tabela 1) foi realizada no Laboratório de Análises Agrícolas (LAGRI). Para análise foi fornecida uma alíquota de $50 \mathrm{~mL}$ de soro de leite, obtida após filtragem em papel filtro quantitativo, seguida de uma centrifugação a $14.000 \mathrm{rpm}$, durante $15 \mathrm{~min}$.

Tabela 1. Composição química do soro de leite

\begin{tabular}{lc}
\hline \multicolumn{1}{c}{ Característica } & Valores \\
Nitrogênio $\left(\mathrm{mg} \mathrm{L}^{-1}\right)$ & 860 \\
Fósforo $\left(\mathrm{mg} \mathrm{L}^{-1}\right)$ & 300 \\
Potássio $\left(\mathrm{mg} \mathrm{L}^{-1}\right)$ & 1500 \\
Sódio $\left(\mathrm{mg} \mathrm{L}^{-1}\right)$ & 370 \\
Cálcio $\left(\mathrm{mg} \mathrm{L}^{-1}\right)$ & 220 \\
Magnésio $\left(\mathrm{mg} \mathrm{L}^{-1}\right)$ & 180 \\
Condutividade elétrica $\left(\mathrm{dS} \mathrm{m}^{-1}\right)$ & 5,5 \\
pH & 4,1 \\
RAS* $\left(\mathrm{mmol} \mathrm{L}^{-1}\right)^{1 / 2}$ & 4,48 \\
\hline * Foi obtida utilizando a fórmula: RAS = Na/[(Ca $+\mathrm{Mg}) / 2]^{1 / 2}$ tendo concentraçôes em mmmol L-1
\end{tabular}

O solo utilizado foi classificado como Neossolo Regolítico distrófico e coletado na camada de 0 a $0,20 \mathrm{~m}$. Para realização das análises física e de fertilidade do solo foram coletadas cinco amostras simples, por meio de tradagem, misturadas, formando uma amostra composta que foi secada ao ar e passada em peneira de malha $2 \mathrm{~mm}$. A caracterização química e física do solo (Tabela 2) foi realizada nos Laboratórios de Fertilidade do Solo e Física do Solo, ambas pertencentes à UFRPE, de conformidade com os métodos descritos pela EMBRAPA (1999).

Como culturas, utilizaram-se o milheto forrageiro (Pennisetum glaucum L.), cultivar Bulk 1 e o sorgo sudão (Sorghum bicolor var. sudanense L.); as sementes de ambas as espécies foram fornecidas pelo Instituto Agronômico de Pernambuco (IPA). 
Tabela 2. Característica física e química do solo utilizado

\begin{tabular}{lc}
\hline Característica & Valores \\
Areia $\left(\mathrm{g} \mathrm{kg}^{-1}\right)$ & 697 \\
Silte $\left(\mathrm{g} \mathrm{kg}^{-1}\right)$ & 147 \\
Argila $\left(\mathrm{g} \mathrm{kg}^{-1}\right)$ & 157 \\
Densidade do solo $\left(\mathrm{kg} \mathrm{dm}^{-3}\right)$ & 1,32 \\
pH em água & 5,84 \\
Potássio $\left(\mathrm{cmol}_{\mathrm{c}} \mathrm{kg}^{-1}\right)$ & 0,18 \\
Sódio $\left(\mathrm{cmol}_{\mathrm{c}} \mathrm{kg}^{-1}\right)$ & 0,04 \\
Cálcio $\left(\mathrm{cmol}_{\mathrm{c}} \mathrm{kg}^{-1}\right)$ & 0,75 \\
Magnésio $\left(\mathrm{cmol}_{\mathrm{c}} \mathrm{kg}^{-1}\right)$ & 0,40 \\
Fósforo $\left(\mathrm{mg} \mathrm{kg}^{-1}\right)$ & 0,80 \\
Matéria orgânica $\left(\mathrm{g} \mathrm{kg}^{-1}\right)$ & 3,58 \\
\hline
\end{tabular}

Dois ensaios foram conduzidos simultaneamente, com delineamento inteiramente ao acaso, em arranjo fatorial $2 \times 5$, quando então foram analisados dois manejos (dose única e parcelada), cinco níveis de soro $\left(0,167,333,667,1000 \mathrm{~m}^{3} \mathrm{ha}^{-1}\right)$, com quatro repetições, totalizando 80 unidades experimentais. As doses de soro foram determinadas com base nos teores de $\mathrm{K}$ presentes no soro e se levando em consideração a análise química do solo. Utilizaram-se 80 vasos com capacidade para 8 $\mathrm{dm}^{3}$, os quais foram perfurados e neles colocado um dreno na parte inferior. Antes de receber o solo, no fundo de cada vaso foram colocadas brita e uma manta geotêxtil, para evitar perda do solo. A massa de solo colocada em cada vaso foi determinada com base na densidade do solo e no volume do vaso, através de uma massa de $10,5 \mathrm{~kg}$ por vaso. Após a colocação do solo nos vasos procedeu-se à saturação do solo com água potável, utilizando-se saturação ascendente. Os vasos foram distribuídos em uma bancada, na qual permaneceram durante a condução do experimento.

Para ambas as culturas, a aplicação de soro de leite foi realizada em dois manejos: dose única aplicada 10 dias antes da semeadura, período necessário para que ocorresse a estabilização da matéria orgânica no solo, e dose parcelada, $50 \%$ da dose única antes da semeadura e os 50\% restantes 20 dias após a emergência das plantas.

Realizou-se a semeadura para as duas culturas colocandose dez sementes por vaso, bem distribuídas, a aproximadamente um centímetro de profundidade. Após a emergência das plantas iniciou-se a rega com água potável, de forma manual e em dias alternados, fornecendo-se a mesma quantidade de água para todos os tratamentos $(800 \mathrm{~mL})$; o lixiviado foi aproveitado e seu volume completado, até atingir os $800 \mathrm{~mL}$. O desbaste ocorreu cinco dias após a germinação, deixando-se as duas plântulas mais vigorosas em cada vaso.

Aos 42 dias após a germinação determinou-se a altura das plantas, medindo-as com auxílio de uma trena métrica, a partir do colo ao ápice do maior perfilho esticado. Após o procedimento fez-se a colheita das plantas através de um corte raso, separando-se a parte aérea das raízes, a nível do solo. A massa fresca da parte aérea (MFPA) foi obtida logo após o corte, quando todo o material foi colocado em sacos de papel e pesado; em seguida, o material foi encaminhado para estufa de circulação forçada de ar para secagem a $65^{\circ} \mathrm{C}$, até atingir peso constante, quando foi novamente pesado para obtenção da massa seca da parte aérea (MSPA).
Para determinar as concentrações dos nutrientes presentes na parte aérea das duas culturas, fez-se a trituração da matéria seca em moinho tipo Wiley, seguindo-se o preparo dos extratos específicos para as determinações analíticas dos nutrientes, conforme a metodologia descrita por Bezerra Neto \& Barreto (2004). As determinações de P, K, Na, Ca e Mg foram realizadas no extrato nitroperclórico, cujo $\mathrm{P}$ foi quantificado colorimetricamente pelo método do molibdo-vanadato; o N único foi determinado após digestão sulfúrica, por destilação em aparelho Kjeldahl e quantificação por titulação; K e Na por fotometria de chama e $\mathrm{Mg}$ e Ca por absorção atômica (EMBRAPA, 1999).

Os dados obtidos foram submetidos à análise de variância e, quando necessário, utilizada análise de regressão para descrever o efeito das doses (Gomes, 2000).

\section{RESULTADOS E DISCUSSÃO}

A aplicação do soro de leite no solo apresentou efeito significativo $(\mathrm{P} \leq 0,05)$ sobre a altura do milheto para dose $\mathrm{e}$ interação. No entanto, o manejo analisado individualmente não foi significativo mas no manejo de aplicação dose única o tratamento equivalente a $333 \mathrm{~m}^{3} \mathrm{ha}^{-1}$ proporcionou a altura máxima registrada e, para a aplicação parcelada, a dose equivalente a $167 \mathrm{~m}^{3} \mathrm{ha}^{-1}$. Utilizando-se a análise de regressão obteve-se um $R^{2}$ igual a $0,49\left(y=-0,0006 x^{2}+0,019 x+65,47\right)$ e $0,32\left(y=-0,00009 x^{2}+0,0916 x+44,59\right)$ para aplicações dose única e parcelada, respectivamente.

Em relação ao sorgo, o efeito foi significativo $(\mathrm{P} \leq 0,05)$ apenas para as doses. Observou-se que a dose equivalente a $167 \mathrm{~m}^{3} \mathrm{ha}^{-1}$ promoveu um aumento na altura das plantas quando comparada com a testemunha. O modelo que melhor descreveu este resultado foi o quadrático, de acordo com as equações de regressão (Figura 1).

Nota-se que as doses superiores a $333 \mathrm{~m}^{3} \mathrm{ha}^{-1}$ na aplicação em dose única para o milheto e $167 \mathrm{~m}^{3} \mathrm{ha}^{-1}$ de forma parcelada, tanto para o milheto quanto para o sorgo, causaram diminuição na altura fato devido, provavelmente, ao aumento de sais no

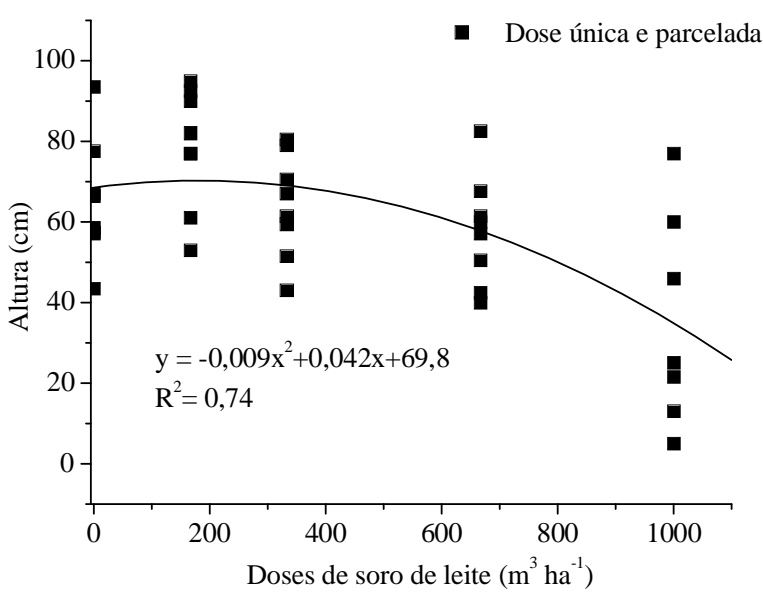

Figura 1. Altura do sorgo cultivado em função da aplicação de doses de soro de leite, nos manejos de fertil lização com dose única e parcelada 
solo, uma vez que apresentou $\mathrm{CE}_{\mathrm{es}}$ elevada. Os resultados encontrados para o milheto e o sorgo corroboram com os valores encontrados por Gheri et al. (2003) quando trabalharam com soro de leite ácido na produção de Panicum maximum Jacq. cv. Tanzânia, ao observarem aumento na altura das plantas com a aplicação das maiores doses (225 e $\left.300 \mathrm{~kg} \mathrm{ha}^{-1}\right)$.

A análise de variância aplicada à matéria seca da parte aérea apresentou efeito significativo $(\mathrm{P}<0,05)$ para a dose e manejo, tal como para sua interação em ambas as culturas. A produção de MSPA promovida pela adição de doses crescentes de soro de leite foi descrita pelo modelo quadrático (Figura 2).

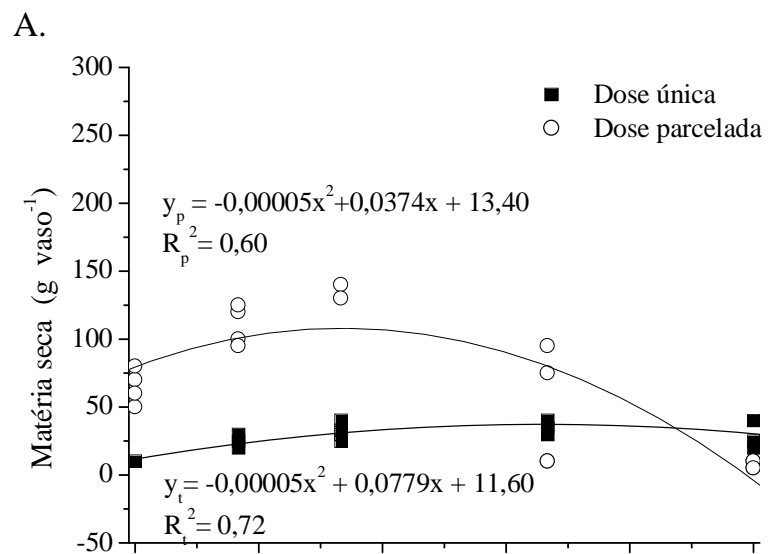

B.

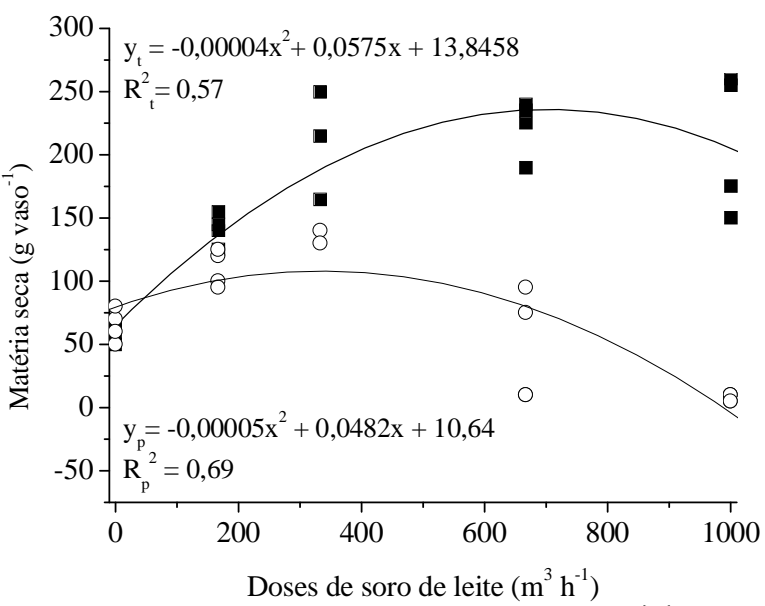

Figura 2. Massa seca da parte aérea de milheto $(A)$ e sorgo (B) cultivado em função da aplicação de doses de soro de leite, nos manejos de fertilização dose única e parcelada

Para a cultura do milheto na aplicação parcelada, o acúmulo máximo de matéria seca da parte aérea ocorreu na dose equivalente a $370 \mathrm{~m}^{3} \mathrm{ha}^{-1}$. No manejo de aplicação parcelada dose única, a produção máxima foi obtida com a dose equivalente a $779 \mathrm{~m}^{3} \mathrm{ha}^{-1}$ de soro. A partir das doses citadas observou-se redução no rendimento de matéria seca da parte aérea, nos dois manejos, o que pode ser devido a um desequilíbrio nutricional, uma vez que o soro de leite era a única fonte de nutrientes utilizada. Em relação à cultura do sorgo, nas aplicações dose parcelada e dose única, a máxima produção de matéria seca da parte aérea ocorreu com as doses equivalentes a 718 e $482 \mathrm{~m}^{3} \mathrm{ha}^{-1}$ de soro.

Matos et al. (2003) verificaram no cultivo de forrageiras, ao estudar a aplicação de água residuária da lavagem e despolpa dos frutos do cafeeiro, que também é rica em potássio, que dentre as plantas analisadas o milheto apresentou rendimento de matéria seca muito próximo aos obtidos com a aplicação de água de boa qualidade complementada com adubação convencional. Araújo et al. (2009), ao avaliarem o fornecimento de nutrientes por compostos orgânicos semicurados aplicados ao solo, também incrementaram a produção de massa seca de Brachiaria decumben.

$\mathrm{Na}$ cultura do sorgo observou-se comportamento semelhante ao do milheto, a partir da dose equivalente a $667 \mathrm{~m}^{3} \mathrm{ha}^{-1}$ visto que ambos os manejos de aplicação comprometeram o desenvolvimento das duas culturas, chegando a promoveu a morte, na maioria das plantas. $\mathrm{O}$ resultado, sem dúvida, foi devido à toxidez, o que corrobora com a recomendação de Modler (1987), de que a maior dose de soro de leite aplicada ao solo por ano deve ficar entre 625 a $950 \mathrm{~m}^{3} \mathrm{ha}^{-1}$.

$\mathrm{O}$ acúmulo de $\mathrm{P}$ na planta, promovido pela adição do soro de leite ao solo, foi descrito pelo modelo quadrático (Figura 3). Houve interação significativa $(\mathrm{P} \leq 0,05)$ na cultura do milheto entre as doses e os manejos adotados para a aplicação de soro de leite; entretanto, avaliando-se as variáveis isoladas, tem-se que apenas a dose de aplicação foi significativa para ambas as culturas. Para a cultura do milheto verifica-se que com aplicação da dose única as plantas continuaram a acumular $\mathrm{P}$ até a dose máxima estudada (equivalente a $1000 \mathrm{~m}^{3} \mathrm{ha}^{-1}$ de soro). Para o sorgo, apenas as doses foram significativas, fato que não ocorreu com o manejo aplicado.

Os valores encontrados foram superiores aos considerados adequados para a cultura do milho (2,5 a $3,5 \mathrm{~g} \mathrm{~kg})$ e do sorgo (4,0 a 8,0 g kg), IPA (2008). Os valores de fósforo encontrados foram superiores quando comparados com os da testemunha, corroborando os com resultados encontrados por Erthal et al. (2010); ao estudarem a aplicação de água residuária da bovinocultura no solo, notaram que a concentração de $\mathrm{P}$ nas forrageiras avaliadas foi superior à obtida na testemunha.

Avaliando-se os teores de Na para o milheto, observou-se significância (P d" 0,05) tanto para interação entre doses e manejos de aplicação quanto para as variáveis analisadas isoladamente. Para o sorgo, o comportamento foi semelhante. $\mathrm{O}$ aumento nos teores de sódio promovidos pela adição de doses de soro de leite foi descrito pelo modelo quadrático (Figuras 4). De acordo com as equações de regressão, o maior acúmulo de $\mathrm{Na}$ nas culturas estudadas ocorreu na dose equivalente a $1000 \mathrm{~m}^{3} \mathrm{ha}^{-1}$ de soro, para os dois manejos.

Ao fazer uma comparação entre os manejos de aplicação do soro, nota-se que na aplicação parcelada a partir da dose equivalente a $667 \mathrm{~m}^{3} \mathrm{ha}^{-1}$ ocorreu um comprometimento no desenvolvimento das plantas para as duas culturas avaliadas. Deduz-se que o resultado tenha sido devido ao acúmulo de sais no solo, principalmente $\mathrm{Na}$, uma vez que o íon foi encontrado em altas concentrações na parte aérea das plantas. Garcia et al. (2007) e Oliveira et al. (2009) verificaram aumento da concentração de sódio na parte aérea de plantas de milho cultivado em ambientes salinos. Segundo Blumwald (2000), quando o $\mathrm{Na}$ está em altas concentrações no solo é considerado potencialmente tóxico para as plantas. Munns (2002) relata que, em geral, o Na restringem o crescimento, seja 
A.

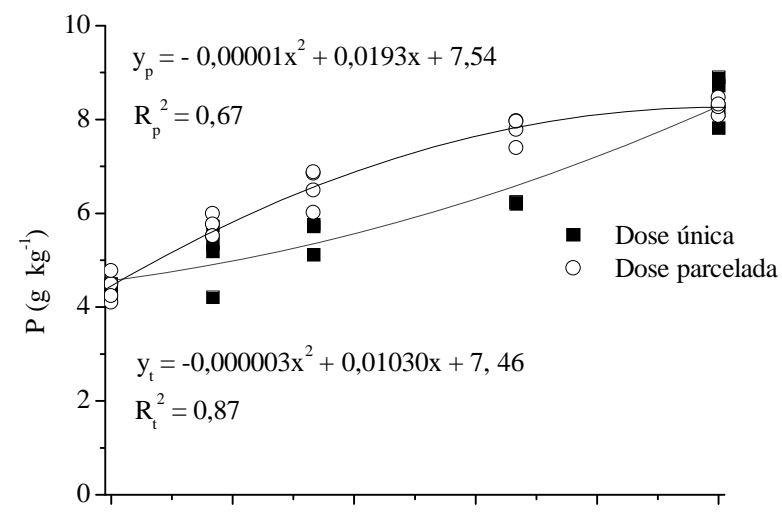

B.

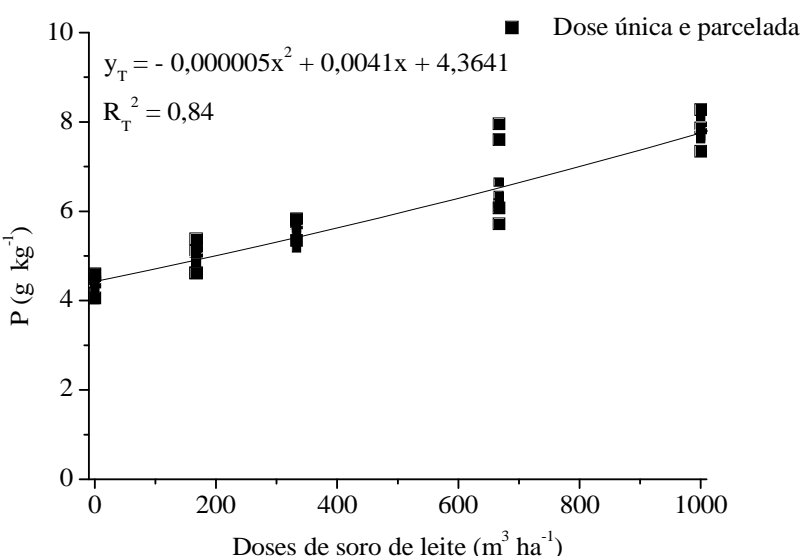

Figura 3. Teores de $P$ no milheto $(A)$ e sorgo (B), cultivados em função da aplicação de doses de soro de leite nos manejos de fertilização dose única e parcelada

da parte aérea como do sistema radicular das plantas, em decorrência de efeitos osmóticos, passíveis de acarretar déficit hídrico e efeitos específicos de íons, que resultam em toxidez ou desordens nutricionais.

Com relação ao teor $\mathrm{K}$ no milheto, não houve efeito significativo $(P \geq 0,05)$ para dose, manejo e interação.

Ao fazer uma comparação entre os manejos de aplicação do soro, nota-se que na aplicação parcelada a partir da dose equivalente a $667 \mathrm{~m}^{3} \mathrm{ha}^{-1}$ ocorreu um comprometimento no desenvolvimento das plantas para as duas culturas avaliadas. Deduz-se que o resultado tenha ocorrido ao acúmulo de sais no solo, principalmente $\mathrm{Na}$, uma vez que o íon foi encontrado em altas concentrações na parte aérea das plantas. Garcia et al. (2007) e Oliveira et al. (2009) verificaram aumento da concentração de sódio na parte aérea de plantas de milho cultivado em ambientes salinos. Segundo Blumwald (2000), quando o $\mathrm{Na}$ está em altas concentrações no solo é considerado potencialmente tóxico para as plantas. Munns (2002) relata que o Na normalmente restringem o crescimento tanto da parte aérea como do sistema radicular das plantas, em decorrência de efeitos osmóticos, que podem acarretar déficit hídrico, e efeitos específicos de íons, que resultam em toxidez ou desordens nutricionais.

Com relação ao teor $\mathrm{K}$ no milheto, não houve efeito significativo $(P \geq 0,05)$ para dose, manejo e interação.

$\mathrm{O} \mathrm{K}$ apresentou efeito significativo $(\mathrm{P}<0,05)$ para dose aplicada apenas para cultura do sorgo, obtendo-se $u m \mathrm{R}^{2}$ igual
A.

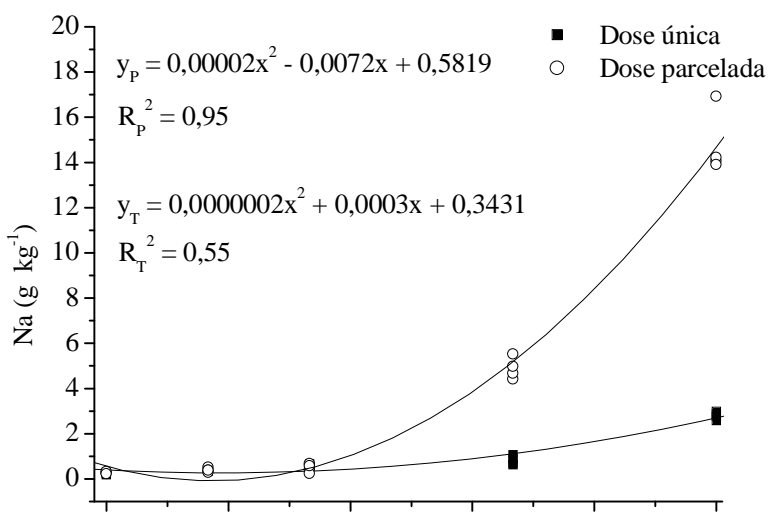

B.

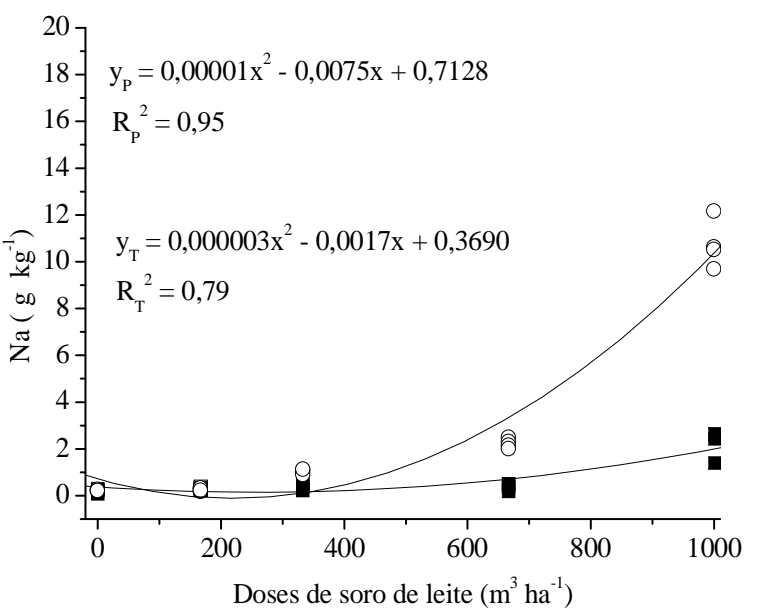

Figura 4. Teores de sódio no milheto (A) e sorgo (B), cultivados em função da aplicação de doses de soro de leite, nos manejos de fertilização dose única e parcelada

a $0,29\left(y=-0,00003 x^{2}-0,011 x+88,45\right)$, verifica-se que a partir das maiores doses de soro $\left(667 \mathrm{~m}^{3} \mathrm{ha}^{-1}\right)$, houve redução no acúmulo, isto se deve ao fato de já haver grande quantidade do íon na planta, uma vez que os teores de K encontrados ficaram acima do considerado adequado para a cultura do sorgo que varia de 25,0 a 30,0 $\mathrm{g} \mathrm{kg}^{-1}$, IPA (2008); este fato deve ter ocorrido em razão da grande quantidade do íon contido no soro utilizado. Os resultados obtidos foram o inverso dos observados por Jones et al. (1993), quando trabalharam com aplicação $100 \mathrm{~mm}$ (maior dose) de soro de leite no solo e Mélo et al. (2005); Saraiva et al. (2007) observaram, quando aplicaram a manipueira que possui $292 \mathrm{mg} \mathrm{L}^{-1} \mathrm{de} \mathrm{K}$, no solo, aumento no teor de potássio, tanto no solo como na planta, com o aumento das doses aplicadas (maiores doses equivalente a 510 e 632 $\mathrm{m}^{3} \mathrm{ha}^{-1}$, respectivamente).

Ao relacionar o acúmulo de K com o Na observado nota-se que, apesar da planta ter acumulado muito $\mathrm{Na}$, não foi evidenciada redução no teor de Kque pudesse ser considerada em decorrência do Na pois, à medida em que o lixiviado estava sendo reaproveitado, eram fornecidos sódio e potássio. Estudos têm indicado o efeito competitivo entre $\mathrm{Na}$ e K, assim como a seletividade pelo íon e sua relação com a sensibilidade das plantas à salinidade. Azevedo Neto \& Tabosa (2000), relataram que o aumento na concentração de sódio do meio externo ocasiona a diminuição dos teores de potássio nos tecidos das plantas de milho. 
Para o Ca observou-se, na cultura do milheto, efeito significativo $(\mathrm{P} \leq 0,05)$ para a dose e o manejo de aplicação e para sua interação, enquanto para o sorgo apenas as doses foram significativas. $\mathrm{O}$ acúmulo de cálcio na parte aérea das plantas foi descrito pelo modelo quadrático (Figura 5) o qual mostrou que, no milheto para o manejo parcelado, a dose que mais acumulou Ca foi equivalente a $800 \mathrm{~m}^{3} \mathrm{ha}^{-1}$ de soro, sendo observada uma redução a partir desta dose.

A.

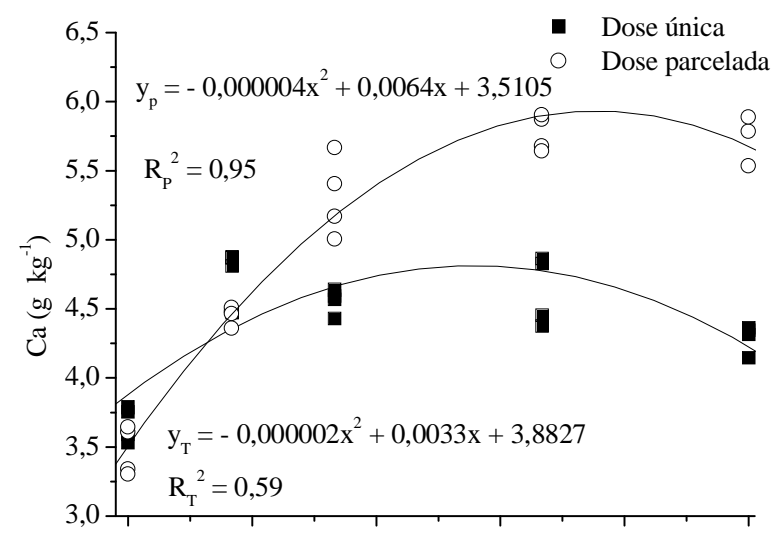

B.

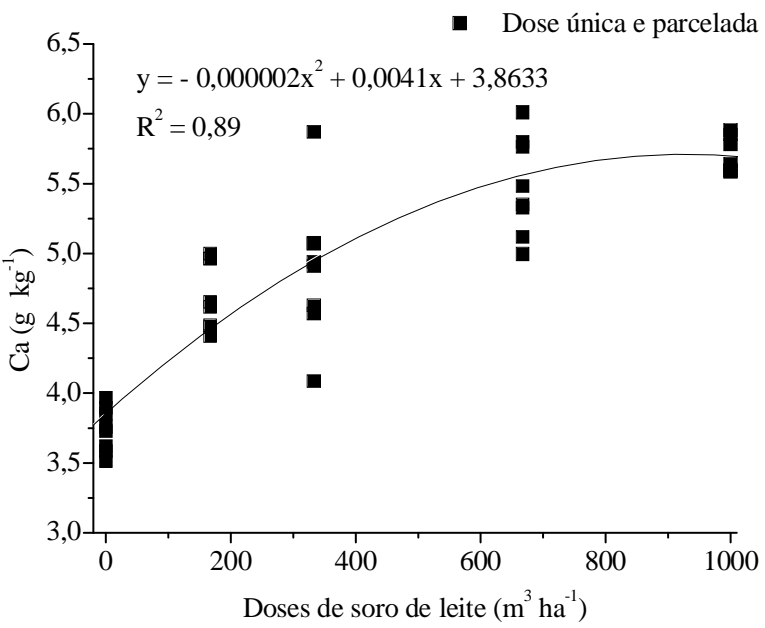

Figura 5. Teores de $C a$ do milheto $(A)$ e sorgo $(B)$ cultivado em função da aplicação de doses de soro de leite, nos manejos de fertilização dose única ( $\mathrm{A}$ e B) parcelada

Em referência ao sorgo ocorreram, na maior dose analisada, $1000 \mathrm{~m}^{3} \mathrm{ha}^{-1}$ de soro. Os teores de Ca encontrados para a cultura do milheto e do sorgo, ficaram dentro da margem considerada adequada para o sorgo (4,0 a 6,0 $\mathrm{g} \mathrm{Kg}^{-1}$ ), segundo IPA (2008).

Apesar de estudos têm demonstrado que a salinidade diminui os teores de cálcio na parte aérea das plantas de milho (Azevedo Neto \& Tabosa, 2000); os autores ainda reportaram, em estudo semelhante, que o aumento no teor de sódio do meio externo ocasiona diminuição dos teores de cálcio nos tecidos das plantas de milho, haja vista que para alguns autores o sódio desloca o cálcio do plasmalema das células radiculares, o que resulta em perda da integridade da membrana e do fluxo citossólico de solutos orgânicos e inorgânicos, comportamento não observado no experimento, uma vez que os teores encontrados não ficaram abaixo dos valores adequados.
Nos teores de Mg observados nota-se que houve efeito significativo $(\mathrm{P}<0,05)$ apenas para as doses aplicadas na cultura do milheto (Tabela 3), embora o sorgo não tenha apresentou efeito significativo $(\mathrm{P}>0,05)$. De acordo com a equação de regressão $\left(\mathrm{y}=-0,000001 \mathrm{x}^{2}+0,0011 \mathrm{x}+3,6751\right)$ obteve-se um $\mathrm{R}^{2}$ de 0,47 e ocorreu acúmulo de $\mathrm{Mg}$ até a maior dose de soro aplicada (equivalente a $1000 \mathrm{~m}^{3} \mathrm{ha}^{-1}$ ). Sabe-se que a taxa de absorção do $\mathrm{Mg}$ pode ser muito afetada por outros cátions, como o K e Ca (Vitti et al., 2006), porém este efeito não foi observado de vez que os valores registrados ficaram dentro dos valores considerados adequados (2,5 a 4,0 $\mathrm{g} \mathrm{k}^{-1}$ ) conforme IPA (2008).

\section{CONCLUSÕES}

1. A utilização de soro de leite no solo aumenta a produção de matéria seca, em ambas às culturas.

2. Dentre os macronutrientes o fósforo proporciona teores acima dos considerados adequados, tanto para o milheto quanto para o sorgo.

3. Os maiores acúmulos de sódio ocorrem com a aplicação da dose equivalente a $1000 \mathrm{~m}^{3} \mathrm{ha}^{-1}$ nos dois manejos de aplicação.

4. No manejo de aplicação parcelada doses superiores a 370 $\mathrm{m}^{3} \mathrm{ha}^{-1}$ para milheto e $480 \mathrm{~m}^{3} \mathrm{ha}^{-1}$ para sorgo, comprometem o desenvolvimento das plantas, mas para dose única,a redução ocorre a partir das doses equivalentes a $779 \mathrm{~m}^{3} \mathrm{ha}^{-1}$ para o milheto e $718 \mathrm{~m}^{3} \mathrm{ha}^{-1}$ para o sorgo.

\section{LITERATURA CITADA}

Aguiar, L. M. S; Moraes, A. V. C.; Guimarães, D. P. Cultivo do sorgo.. Sistemas de produção, 2. Sete Lagoas: Embrapa Milho e Sorgo 3.ed. 2007. 3p.

Almeida, K. E.; Bonassi, I. A.; Roça, R. O. Características físico e químicas de bebidas lácteas. Ciência e Tecnologia de Alimentos, v.21, p.187-192. 2001.

Araújo, F. F.; Tiritan, C. S.; Oliveira, T. R. Compostos orgânicos semicurados na adubação de pastagem degradada de Brachiaria decumbens. Revista Ciência Agronômica, v.40, p.1-6, 2009.

Azevedo Neto, A. D.; Tabosa, J. N. Estresse salino em plântulas de milho: Parte II distribuição dos macronutrientes catiônicos e suas relações com o sódio. Revista Brasileira de Engenharia Agrícola e Ambiental, v.4, p.165-171, 2000.

Barbosa, A. S.; Araújo, A. S.; Florêncio, I. M.; Bezerra, R. R. A.; Florentino, E. R. Estudo cinético da fermentação do soro de queijo de coalho para produção de aguardente. Revista Verde de Agroecologia e Desenvolvimento Sustentável, v.5, p.237-254, 2010.

Bezerra Neto, E.; Barreto, L. P. Métodos de análises químicas em plantas. Recife: UFRPE, 2004. 148p.

Blumwald, E. Sodium transport and salt tolerance in plants. Current Opinion in Cell Biology, v.12, p.431-434, 2000. 
Café, M. B.; Stringhini, J. H.; França, A. F. S. Utilização do milheto na alimentação animal. In: Simpósio sobre ingredientes na alimentação animal, 2, 2002, Uberlândia. Anais.... Uberlândia: Colégio Brasileiro de Nutrição Animal, n.2, 2002. p.5-38.

Capitani, C. D.; Pacheco, M. T. B.; Gumerato, H. F.; Vitali, A. Recuperação de proteínas do soro de leite por meio de conservação com polissacarídeo. Pesquisa Agropecuária Brasileira, v.40, p.1123-1128, 2005.

Castro, C. C. R. Relações planta-animal em pastagem de milheto (Pennisetun americanum (L.) Leeke.) manejada em diferentes alturas com ovinos. Porto Alegre: UFRGS, 2002. 185p. Dissertação Mestrado

EMBRAPA - Empresa Brasileira de Pesquisa Agropecuária. Manual de análises químicas de solos, plantas e fertilizantes. Brasília: EMBRAPA, 1999. 370p.

Erthal, V. J. T.; Ferreira, P. A.; Pereira, O. G.; Matos, A. T. Características fisiológicas, nutricionais e rendimento de forrageiras fertigadas com água residuária de bovinocultura. Revista Brasileira de Engenharia Agrícola e Ambiental, v.14, p.458-466, 2010.

Garcia, G. O.; Ferreira, P. A.; Miranda, G. V.; Neves, J. C. L.; Moraes, W. B.; Santos, D. B. Teores foliares dos macronutrientes catiônicos e suas relações com sódio em plantas de milho sob estresse salino. Idesia, v.25, p.93-106, 2007.

Gheri, E. O.; Ferreira, M. E.; Cruz, M. C. P. Resposta do capimtanzânia à aplicação de soro ácido de leite. Pesquisa Agropecuária Brasileira, v.38, p.753-760, 2003.

Gomes, F. P.; Garcia, C. H. Curso de estatística experimental. 14.ed. Piracicaba: ESALQ, 2000, 477p.

Guimarães, R. I.; Gonçalves, L. C.; Rodrigues, J. A. S. Matéria seca, proteína bruta, nitrogênio amoniacal e pH das silagens de três genótipos de milheto (Pennisetum glaucum (L). R. $\mathrm{Br}$.) em diferentes períodos de fermentação. Revista Brasileira de Milho e Sorgo, v.4, p.251-258, 2005.

Ingrid, H.; Moojen, E. L. Potencial produtivo, alterações da estrutura e qualidade da pastagem de milheto submetida a diferentes níveis de nitrogênio. Revista Brasileira de Zootecnia, v.31, p.875-882, 2002.

IPA - Instituto Agronômico de Pernambuco. Recomendações de adubação para o Estado de Pernambuco. Recife: IPA, 2008. 64p.

Jones, S. B.; Robbins, C. W.; Hansen, C. L., Sodic soil reclamation using cottage cheese (acid) whey. Arid Soil Research and Rehabilitation, v.7, p.51-61, 1993.
Matos, A. T.; Pinto, A. B.; Pereira, O. G.; Soares, A. A.; Lo Monaco, P. A. Produtividade de forragens utilizadas em rampas de tratamento de águas residuárias da lavagem e despolpa dos frutos do cafeeiro. Revista Brasileira de Engenharia Agrícola e Ambiental, v.7, p.154-158, 2003.

Mélo, R. F.; Ferreira, P. A.; Ruiz, H. A.; Matos, A. T.; Oliveira, L. B. Alterações físicas e químicas em três solos tratados com água residuária de mandioca. Irriga, v.10, p.383-392, 2005.

Modler, H. W. The use of whey as animal feed and fertilizer. Bulletin of the International Dairy Federation, n.212, p.111124, 1987.

Munns, R. Comparative physiology of salt and water stress. Plant, Cell and Environment, v.25, p.239-250, 2002.

Oliveira, F. A.; Medeiros, J. F.; Oliveira, M. K. T.; Lima, C. J. G. S.; Almeida Júnior, A. B.; Amâncio, M. G. Desenvolvimento inicial do milho-pipoca irrigado com água de diferentes níveis de salinidade. Revista Brasileira de Ciências Agrárias, v.4, p.149-155, 2009.

Oliveira, J. S.; Ferreira, R. P.; Cruz, C. D.; Pereira, A. V.; Botrel, M. A.; von Pinho, R. G; Rodrigues, J. A. S.; Lopes, F. C. F.; Miranda, J. E. C. Adaptabilidade e estabilidade em cultivares de sorgo. Revista Brasileira deZootecnia, v.31, p.883-889, 2002.

Payne, W. A. Optimizing crop water use in sparse stands of pearl millet. Agronomy Journal, v.92, p.808-814, 2000.

Reis, G. L. Sistema de gestão ambiental em laticínios. Revista Cândido Tostes, v.54, p.35-47, 1999.

Saraiva, F. Z; Sampaio, S. C.; Silvestre, M. G.; Queiroz, M. M. F.; Nobrega, L. H. P.; Gomes, B. M. Uso de manipueira no desenvolvimento vegetativo do milho em ambiente protegido. Revista Brasileira de Engenharia Agrícola e Ambiental, v.11, p.30-36, 2007.

Silva, T. C.; Santos, E. M.; Azevedo, J. A. G.; Edvan, R. L.; Perazzo, A. F.; Pinto, R. M. A.; Rodrigues, J. A. S.; Silva, D. $\mathrm{S}$. Agronomic divergence of sorghum hybrids for silage yield in the semiarid region of Paraiba. Revista Brasileira de Zootecnia, v.40, p.1886-1893, 2011.

Silveira, W. B. Produção de etanol em permeado de queijo: efeito da concentração de substrato e do nível de oxigênio. Viçosa: UFV, 2004. 80p. Dissertação Mestrado

Simili, F. F.; Reis, R. A.; Furlan, B. N.; Paz, C. C. P.; Lima, M. L. P.; Bellingieri, P. A. Resposta do híbrido de sorgo-sudão à adubação nitrogenada e potássica: Composição química e digestibilidade in vitro da matéria orgânica. Ciência Agrotécnica, v.32, p.474-480, 2008.

Vitti, G. C.; Lima, E.; Cicarone, F. Cálcio, magnésio e enxofre. XII. In: Nutrição mineral de plantas. Viçosa: SBCS, 2006. 432p. 